with special reference to agriculture. Dr. Sircar was educated at the Presidency College and the University College of Science, Calcutta. During 1934-36 he worked under Prof. F. G. Gregory, at the Imperial College of Science and Technology, London. After returning to India in 1937 he joined the University College of Science, Calcutta, and took active interest in organizing research in plant physiology, particularly with reference to the rice plant. During 1946-47 Dr. Sircar served as acting head of the Department of Biology in the University of Dacca and from 1949 until 1951 he was on deputation with the Government of India as professor of agricultural botany in the Central College of Agriculture, New Delhi. He has created a strong school of research in Calcutta with special reference to vernalization, photoperiodism, mineral nutrition, germination and auxin relations of the rice plant. In 1954 he was elected a Fellow of the National Institute of Sciences of India. In 1958 he was awarded a travel grant by the Rockefeller Foundation to visit various universities and research institutes in Europe, the United States and Japan. The appointment of Dr. Sircar to the chair is a fitting recognition of his long association with the University of Calcutta and his continued interest in the rice plant.

School of Management Studies, University of Bristol

THE University of Bristol is to establish a School of Management Studies for the purpose of providing residential courses in management studies and for conducting research into problems of business management and administration. This has been made possible by an offer by the Foundation for Management Education to underwrite the sum of $£ 14,500$ a year for a period of seven years in support of the School, and by the agreement of the University Grants Committee to supplement the Foundation's support with a contribution of its own. The initial programme for the School will be the offer of a residential course for executives in the 28-34 age group, who have attained departmental responsibilities and who are nominated by their employers as being suitable for the kind of training which the School will provide. The course will be of eight weeks duration, divided into two periods of four weeks each, these periods being separated by an interval of about ten weeks, during which the students concerned will be expected to undertake specified. studies within their own employing organization. It is intended that the session 1961-62 will be occupied as a preparatory year for the School and its first admissions should be in the autumn term of 1962 . Further information can be obtained from the Registrar, University of Bristol, Bristol 8.

\section{Scientific Literature on Fire}

THE tenth volume of References to Scientific Literature on Fire has recently been published by the Fire Offices' Committee, Joint Fire Research Organization (Library Bibliography No. 5/Part X. By Miss E. M. Shakeshaft and Mrs. B. F. W. Rogowski. Pp. 107. Boreham Wood, Herts : Fire Research Station, 1960). This contains 1,117 title references to papers, most of which appeared in 1956, arranged under eight headings. The largest section (311 references) is entitled "Initiation and Development of Combustion", and refers mainly to original and fundamental studies. Other sections are devoted to branches of fire technology-occurrences of fire (103 references), fire hazards (106), fire precautions (149), fire resistance (178) and fire fighting (229). Short sections headed "Atomic Energy" (18 references ranging from radioisotopes to nuclear weapons) and "General" bring the volume to a conclusion, except for extensive name and subject indexes which occupy as much as two-fifths of the whole publication and have evidently been compiled with much care and thought. There is no doubt that this series fulfils a useful purpose, especially as regards the fire technology references, most of which would not be found in other bibliographies.

\section{Royal Society Committee on Scientific Research in Schools}

ThE Committee on Scientific Research in Schools which was established by the Council of the Royal Society in 1957 has issued a report covering the period November 1, 1959-October 31, 1960. It is stated that interest shown by schools in undertaking research has continued to increase, and the Committee is now administering research projects in 56 schools. Some of these schools have more than one research project under way and a total of 66 separate research projects are now being actively pursued compared with 57 last year. During the year, $£ 2,000$ has been provided by the Council of the Royal Society, and Shell Research Ltd. have given an additional $\mathfrak{£ 7 5}$ for special assistance at one school. All research projects with which the Committee is dealing are carried out with the specialist advice and assistance of Fellows of the Society and by others who act as advisers. The Committee invites further requests from school-masters and school-mistresses for assistance in undertaking research. A list of the schools at which research projects are being carried out and a list of the projects themselves-which cover a very wide range of topics in the physical and biological sciences-are given as an appendix to the report.

\section{North Atlantic Biogeography}

THE American Geographical Society, working together with a panel set up by the Committee on Oceanography of the U.S. National Academy of Sciences-National Research Council, proposes to publish a scientific journal of an unusual kind, tentatively called North Atlantic Biogeography. The journal will consist of maps, accompanied by such explanatory text as may be necessary, and will appear irregularly as contributions are received and accepted. It will be a medium for publication of studies of all kinds-biological, geological, physical, chemical-that will illuminate our geographical understanding of the marine environment. Its scope will be limited to the Atlantic marine areas from the equator to the pole and will include the Aretic basin. The plan is sponsored in the United States by the National Academy of Sciences-National Research Council, and in Canada by the Royal Society of Canada. Funds are being sought in both countries. The panel is international. Further information can be obtained from the Director, American Geographical Society, Broadway at 156th Stroet, Now York 32.

\section{Botanical Garden, Allahabad}

A NEW botanical garden has been established at Allahabad in the premises of the Central Botanical Laboratory, Botanical Survey of India. The garden is divided into various sections such as an economic 